\title{
US Army to use peer review in breast cancer programme
}

Washington. The US Army says it will use a system of peer review modelled on that of the US National Institutes of Health (NIH) to allocate $\$ 210$ million for breast cancer research, allaying fears that it might ignore the wishes of the biomedical community in spending its one-time appropriation.

The approach is described in a report published last week by the Institute of Medicine (IOM) recommending that the money be used for investigator-initiated grants, fellowships and proposals to strengthen the research infrastructure to battle against a disease that will this year kill 46,000 women in the United States. Members of the IOM panel say that it could also help to defuse the issue of 'pork-barrel' science by serving as a model for other US government agencies given money for programmes not directly connected to their missions.

"All of it makes sense to us", says Colonel Fred Tyner, deputy to General Richard Travis, commander of the US Army Medical Research and Development Command at Ft Detrick, Maryland, about the report his office requested. Writing to the panel, Travis said that the report "achieves all of our goals", namely, to obtain advice on the types of programmes most likely to reduce morbidity and mortality in breast cancer and on ways to select the best proposals.

The Army must report to Congress on its plans by 1 June, in accordance with rules requiring it to commit the money by 30 September 1994 and prohibiting its use for new facilities or for large programme grants. Senator Tom Harkin (Democrat, Iowa), whose amendment resulted in an eightfold increase in 1993 for a small Army programme to combat breast cancer, said last week that he hopes "these recommendations will ensure that this money is well-spent".

The centrepiece of the IOM recommendation is a programme of investigator-initiated research costing at least $\$ 150$ million, most of it spent on four-year awards that would be similar to a standard NIH grant. It estimates that 160 such awards could be made, some to people already being supported by the federal government. It proposes 30 smaller, shorter awards for investigators with "innovative and exploratory" proposals - in other words, speculative work with a potentially large return - and 25 awards to young investigators with little experience.

Although the panel did not list specific types or areas of research, it said that the work should address such questions as the genetic component of the disease, changes in cellular and molecular functioning, the impact of risk factors at the molecular level and the application of such knowledge "to improve detection, diagnosis, prevention, treatment and follow-up care". It emphasized that some of the work could involve other types of cancer or fundamental ques-

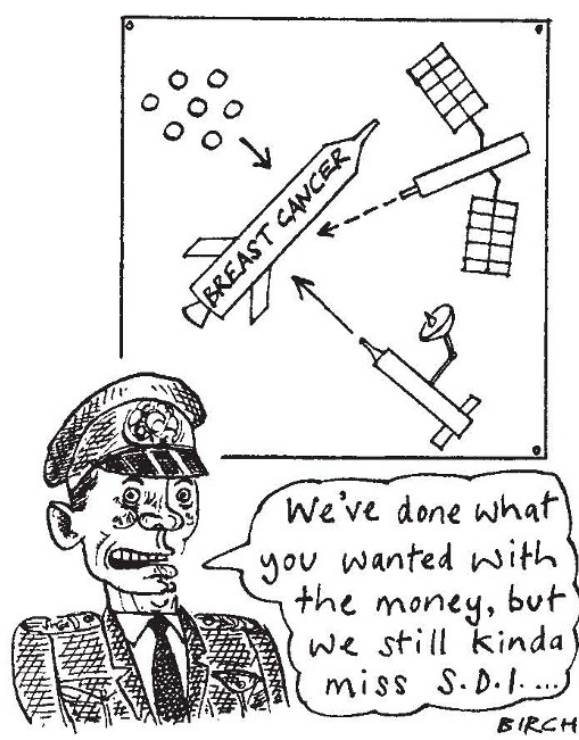

tions that shed light on the disease. It is silent on the proper balance between clinical and laboratory research, believing instead, as panellist Harold Varmus of the University of California, San Francisco, explains, that "quality should be the guiding principle".
The panel also proposes a $\$ 27$-million programme of training and recruitment to attract talented scientists of varying backgrounds into the field. "We do not feel that NCI [the National Cancer Institute] is doing a bad job", says panel chair Suzanne Oparil, a cardiologist at the University of Alabama, Birmingham, "but we want to take advantage of this new money to try something new. Kay Dickersin, an epidemiologist at the University of Maryland School of Medicine, says that "we want to bring in new people and test out some crazy ideas".

One element would offer 50 paid 'instant sabbaticals' to scientists in mid-career, and another would sponsor a dozen or more interdisciplinary meetings. There would also be money for predoctoral traineeships at universities and portable fellowships at both the pre- and post-doctoral levels. "We want everybody to realize that breast cancer is a big problem and we want to encourage them to get involved", says Varmus.

Regardless of the type of programmes offered, there is general agreement that the crucial element is the calibre of the people who will run them and who will administer the peer-review panels. Panel members say that the Army must go outside its ranks to find people with the necessary experience in the field and familiarity with the peer-review process, and Tyner agrees. "We're not breast-cancer experts", he says. "We need to find good people, and I don't expect them already to be on board." Jeffrey Mervis

\section{Russian budget allows for more grants}

Moscow. The government-supported Russian Foundation of Basic Research has given out ten times the expected number of grants to individual researchers after the Russian government significantly increased its 1993 science budget.

The new foundation (see Nature 361, $485 ; 1993)$ has awarded 3,000 grants to groups of seven to nine scientists in six broad areas; physicists received 20 per cent of the total, with the remainder divided equally among the fields of mathematics, chemistry, biology, earth sciences and the humanities. The larger number of awards was made possible by a decision of the government to increase more than threefold the initial request of 250 billion rubles (US $\$ 500$ million) for science.

Although the foundation went to some length to conduct an independent review of the proposals it received, including on-site visits to many institutions, it has been criticized for showing favouritism to those who served on its review panels. Alexander Zakharov, one of the leaders of the professional union of scientists at the Russian Academy of Sciences, says that, as a rule, scientists involved in the selection process not only received grants themselves but also secured funding for coworkers. The review panels were headed by members of the foundation's governing council, who were ineligible for the awards.

The president of the foundation, Andrei Gonchar, does not dispute such allegations and sees nothing wrong with the practice. "I believe that an invitation to a scientist to become an expert means a priori that such a scientist is worthy of support if he submits a grant proposal", Gonchar says. The same is true for officials at the Russian Academy of Sciences, including president Yuri Osipov, who Gonchar says were chosen not because of their prominent positions but because they are good scientists.

Vladimir Pokrovsky 